BMJ Open

Diabetes

Research

\& Care

\title{
Prevalence of undiagnosed diabetic retinopathy among inpatients with diabetes: the diabetic retinopathy inpatient study (DRIPS)
}

\author{
Jessica J Kovarik, ${ }^{1}$ Andrew W Eller, ${ }^{1}$ Lauren A Willard, ${ }^{2}$ Jiaxi Ding, ${ }^{2}$ \\ Jann M Johnston, ${ }^{3}$ Evan L Waxman ${ }^{1}$
}

To cite: Kovarik JJ, Eller AW, Willard LA, et al. Prevalence of undiagnosed diabetic retinopathy among inpatients with diabetes: the diabetic retinopathy inpatient study (DRIPS). BMJ Open Diabetes Research and Care 2016;4: e000164. doi:10.1136/ bmjdrc-2015-000164

This study was presented in abstract form as a poster presentation at the Annual Meeting of the Association for Research in Vision and Ophthalmology, May 2012.

Received 12 October 2015 Revised 11 December 2015 Accepted 2 January 2016

This final article is available for use under the terms of the Creative Commons Attribution Non-Commercial 3.0 Licence; see http://drc.bmj.com

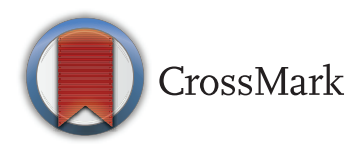

For numbered affiliations see end of article.

Correspondence to Dr Evan L Waxman; waxmane@upmc.edu

\section{ABSTRACT}

Objective: To determine the prevalence and risk factors of diabetic retinopathy in the inpatient diabetic population in the USA and to determine the barriers to ophthalmic examinations and treatment among this population.

Research design and methods: A cross-sectional analysis of 113 inpatients with diabetes mellitus admitted to an inner city community teaching hospital in Pittsburgh. Digital fundus photographs of the posterior pole were taken of each eye after pharmacological dilation. Presence, absence and severity of diabetic retinopathy and macular edema were graded on the basis of internationally accepted criteria. An investigatoradministered questionnaire and review of the medical record were used to obtain data about patient demographics, clinical characteristics and barriers to ophthalmic care. The association between these data and the presence of diabetic retinopathy was tested.

Results: The estimated prevalence of diabetic retinopathy in the inpatient population was $44 \%(95 \% \mathrm{Cl}$ $34 \%$ to $53 \%$ ). The prevalence of previously undiagnosed diabetic retinopathy and sight-threatening retinopathy was $25 \%$ (95\% Cl 17\% to $33 \%$ ) and $19 \%$ (95\% Cl $11 \%$ to $26 \%$ ), respectively. Renal disease was independently associated with the presence of diabetic retinopathy (OR, 3.86; $95 \% \mathrm{Cl} 1.22$ to 12.27), as well as a longer duration of diabetes (OR, 1.08 per year; $95 \% \mathrm{Cl} 1.014$ to 1.147 ). Diabetic retinopathy was seen in 15 of 17 patients admitted with diabetic foot ulcers or osteomyelitis. Frequently reported barriers to ophthalmic examinations included lack of transportation and physical disability.

Conclusions: The prevalence of diabetic retinopathy and sight-threatening diabetic retinopathy in the inpatient population is likely significantly higher than in the general diabetic population in the USA. These patients have barriers to care that need to be addressed to make standard of care ophthalmic examinations and treatment possible in this population.

\section{INTRODUCTION}

Diabetic retinopathy is the leading cause of new cases of blindness in US adults aged 2074 years. ${ }^{1}$ Evidence indicates that with timely

\section{Key messages}

- The prevalence of retinopathy in diabetic inpatients was significantly higher than in an outpatient population and one quarter of inpatients with diabetes were noted to have previously undiagnosed retinopathy.

- A history of renal disease and admission for non-healing ulcer were strongly correlated with the presence of retinopathy.

- Patient education and awareness were less important barriers to care than were transportation and physical disability in this population.

diagnosis and appropriate care, $50-70 \%$ of vision loss from diabetes can be prevented. ${ }^{2-7}$ Moreover, standard of care screening and treatment of diabetic retinopathy prevents needless vision loss and is also cost-effective, with potential savings of $\$ 600$ million in the USA annually. ${ }^{8}$ Current guidelines from the American Diabetes Association indicate that all patients with type 1 diabetes should have a dilated eye examination within 5 years of diagnosis and annually thereafter; and all patients with type 2 diabetes should have a dilated eye examination at the time of diagnosis and annually thereafter. ${ }^{9}$ Owing to various reasons such as lack of knowledge, affordability and time, ${ }^{10}$ ophthalmic care for many patients with diabetes remains less than optimal and many develop severe and irreversible visual impairment.

The current estimated prevalence of diabetic retinopathy and sight-threatening diabetic retinopathy among US diabetics is $28.5 \%$ and $4.4 \%$, respectively. ${ }^{11}$ Currently, there are no documented studies that have reported the prevalence of diabetic retinopathy among diabetic inpatients in US hospitals. In particular, there are no data regarding the prevalence of undiagnosed and sight-threatening diabetic retinopathy in this high-risk population. A PubMed search 
failed to identify previously published data, indicating the barriers to ophthalmic care for this high-risk population. Knowledge of these barriers could assist in addressing shortcomings in diagnosis and treatment. The inpatient population is generally a sicker population with more associated comorbidities. Our objective in the current work was to determine the prevalence and risk factors of diabetic retinopathy in the inpatient diabetic population in the USA and to determine the barriers to ophthalmic examinations and treatment among this population.

\section{METHODS}

This study protocol was approved by the University of Pittsburgh Institutional Review Board and informed written consent was obtained from all participants.

\section{Study population}

Between 1 September 2011 and 31 August 2012, 113 consecutive eligible inpatients with a known diagnosis of diabetes mellitus were enrolled in this cross-sectional study at UPMC Mercy Hospital in Pittsburgh, an inner city community teaching hospital. Participants were selected from an inpatient diabetes census according to a computer-generated randomisation table. Of those randomly selected, only those who fulfilled predetermined inclusion criteria were invited to participate in the study. Women and men $\geq 18$ years, admitted to UPMC Mercy Hospital with type 1 or 2 diabetes on the basis of either a previous diagnosis made by a physician or hemoglobin $\mathrm{A} 1 \mathrm{C} \geq 6.5 \%(48 \mathrm{mmol} / \mathrm{mol})$, were eligible for participation. Exclusion criteria included patients with type 1 diabetes diagnosed within the past 5 years as these patients would not be expected to have retinopathy; patients who were too ill or debilitated to participate in a bedside photographic examination; and cases of known pregnancy, in order to eliminate the potential confounder of gestational diabetes.

\section{Clinical and demographic data}

An investigator-administered questionnaire and review of the medical record were used to obtain data about secondary risk factors for retinopathy including duration of diabetes, hemoglobin A1C, and associated comorbidities: hypertension, coronary artery disease, hyperlipidemia, renal disease, and peripheral neuropathy/ peripheral vascular disease. Patients were recorded as having these comorbidities if they self-reported them or if they appeared on a review of the record. Hemoglobin A1C values recorded were the most recent ones found on review of the electronic health record. The type of diabetes, that is, type 1 or type 2 , and admission diagnoses were recorded. Gender, age, race/ethnicity, education, family income, and insurance status were recorded. Patients were asked whether they had an ophthalmologist; when they had their last dilated fundus examination; whether or not they had been diagnosed with diabetic retinopathy in the past; and whether or not they knew diabetes could affect vision. Participants who had not had a dilated fundus examination in more than a year were interviewed for barriers to ophthalmic care. Patients were asked whether they had a primary care physician, an endocrinologist, a cardiologist, a nephrologist and/or a podiatrist.

\section{Fundus photography}

Each participant underwent a retinal screening examination via digital fundus photography after pharmacological dilation with $0.5 \%$ tropicamide. Nonstereoscopic, $45^{\circ}$ single-field images of the posterior pole, which included the macula, major vascular arcades, and optic nerve, were captured. Examinations were performed at the bedside. Patients were required to sit up, position their chin at a chin rest and hold still long enough for the photograph.

Two ophthalmologists graded the photos independently. Both were masked to the demographic data and medical history. When there was discordance between the readers, they reviewed the images and agreed on the final interpretation.

Each individual fundus photograph was graded lesion by lesion, and the severity of retinopathy was determined using the proposed new international classification of diabetic retinopathy. ${ }^{12}$ Diabetic retinopathy was classified into five severity levels: (1) no retinopathy, (2) mild nonproliferative, (3) moderate non-proliferative, (4) severe non-proliferative, and (5) proliferative diabetic retinopathy (PDR). Diabetic macular edema was classified as clinically significant macular edema (CSME) or non-CSME, based on the Early Treatment Diabetic Retinopathy Study criteria, without stereoscopic images. For purposes of this study, those images with hard exudates within 500 microns of the foveal center, or a cluster of exudates greater than 1 disc diameter in size within 1 disc diameter of the foveal center, were classified as CSME. Certain photos were marked as ungradable as deemed necessary by the reviewers. The severity of retinopathy in each participant was determined by the eye with worse disease. Sight-threatening disease was defined as severe non-proliferative diabetic retinopathy (NPDR), PDR or CSME.

\section{Patient education}

All patients were given an explanation of diabetic retinopathy, its potential to cause visual impairment, and the importance of regular follow-up examinations. All patients were informed of the results and limitations of their retinal screening examination before hospital discharge. All available treatment options were offered to those who could benefit from intervention. After obtaining a written consent about the disclosure of information, each study patient's primary care physician and/or endocrinologist was informed of the diagnosis and recommended treatment and/or follow-up via letter. 


\section{Analysis}

The sample size calculation was based on determining the prevalence of undiagnosed diabetic retinopathy in an inpatient population, which we estimated to be $20 \%$. Therefore, to estimate a $95 \%$ CI with $7.5 \%$ precision, 110 patients were required for the study.

Data were analyzed using SPSS statistical software. The primary analysis sought to determine the prevalence of diabetic retinopathy in the inpatient setting. A secondary analysis sought to examine the barriers to standard of care diabetic retinopathy screening examinations. Logistic regression was used to detect the independent factors associated with diabetic retinopathy. First, we examined univariate relationships between each variable and the presence of diabetic retinopathy. Multivariable logistic regression with backward stepwise variable selection was used to see which variables could independently explain the presence of diabetic retinopathy. For continuous variables, we used the non-parametric t test. For categorical variables, we used the $\chi^{2}$ test. An exploratory analysis looked at the subspecialists involved in the care of this study population.

Of the 113 patients enrolled in the study, three patients were physically unable to take photos after being initially deemed eligible to do so, and two patients decided to have photos of insufficient quality to be graded. These five patients were therefore excluded from the calculation of the prevalence of retinopathy $(n=108)$. They were also excluded from the regression analysis to determine factors predictive of diabetic retinopathy. They were, however, included in the analysis of barriers to care.

\section{RESULTS}

The clinical and demographic characteristics of the 113 patients enrolled in the study are summarized in table 1.

The prevalence of retinopathy and classification data are listed in tables 2 and 3 .

Figure 1 shows the barriers to standard of care diabetic retinopathy screening examinations as reported by those patients who did not have a dilated fundus examination within the previous year.

Lack of knowledge that diabetes can affect vision was reported by $9 \%(10 / 113)$ of patients. A dilated eye examination within the past year was reported by $40 \%$ $(45 / 113)$ of patients and $5 \%(6 / 113)$ of patients reported never having had a dilated fundus examination.

Baseline clinical and demographic features were tested for association with diabetic retinopathy in a univariate analysis (table 4 ).

Of these, renal disease (OR, 3.86; 95\% CI 1.22 to 12.27; $\mathrm{p}=0.022$ ) and longer duration of diabetes (OR, 1.08 per year duration; $95 \%$ CI 1.014 to 1.147 ; $\mathrm{p}=0.017$ ) were independently associated with the presence of diabetic retinopathy in the multivariable analysis. Additionally, 15 of $17(88.2 \%)$ patients who were
Table 1 Demographic and clinical characteristics of study patients

\begin{tabular}{|c|c|}
\hline & n (\%) \\
\hline \multicolumn{2}{|l|}{ Sex } \\
\hline Male & $52(46)$ \\
\hline Female & $61(54)$ \\
\hline \multicolumn{2}{|l|}{ Age (years) } \\
\hline$<50$ & $20(18)$ \\
\hline $50-60$ & $34(30)$ \\
\hline $61-70$ & 22 (19) \\
\hline $71-80$ & $24(21)$ \\
\hline$>80$ & $13(12)$ \\
\hline \multicolumn{2}{|l|}{ Race } \\
\hline Black & $30(27)$ \\
\hline White & $83(73)$ \\
\hline \multicolumn{2}{|l|}{ Education } \\
\hline High (>12 years) & $52(46)$ \\
\hline Low (<12 years) & $61(54)$ \\
\hline \multicolumn{2}{|l|}{ Annual Income (\$) } \\
\hline$<25000$ & $65(58)$ \\
\hline $25001-50000$ & $34(30)$ \\
\hline $50001-75000$ & $5(4)$ \\
\hline $75001-100000$ & $4(4)$ \\
\hline$>100000$ & $4(4)$ \\
\hline \multicolumn{2}{|l|}{ Health insurance } \\
\hline Yes & $101(89)$ \\
\hline No & $12(11)$ \\
\hline \multicolumn{2}{|l|}{ Ophthalmologist } \\
\hline Yes & $72(64)$ \\
\hline No & $41(36)$ \\
\hline \multicolumn{2}{|c|}{ Last dilated fundus examination } \\
\hline$<1$ year & $45(40)$ \\
\hline$>1$ year & $60(53)$ \\
\hline Never & $6(5)$ \\
\hline Not sure & $2(2)$ \\
\hline \multicolumn{2}{|c|}{ Knowledge that DR can affect vision } \\
\hline Yes & $103(91)$ \\
\hline No & $10(9)$ \\
\hline \multicolumn{2}{|l|}{ Type of diabetes } \\
\hline Type 1 & $5(4)$ \\
\hline Type 2 & $108(96)$ \\
\hline \multicolumn{2}{|l|}{ Duration of diabetes } \\
\hline Recent ( $\leq 10$ years) & $61(54)$ \\
\hline Not recent ( $>10$ years) & 44 (39) \\
\hline Unknown & $7(6)$ \\
\hline \multicolumn{2}{|l|}{$\mathrm{A} 1 \mathrm{C} \%(\mathrm{mmol} / \mathrm{mol})$} \\
\hline$<6.5(48)$ & $21(19)$ \\
\hline $6.5-8.5(48-69)$ & $38(34)$ \\
\hline $8.6-10.5(70-91)$ & $14(12)$ \\
\hline$>10.5(91)$ & $16(14)$ \\
\hline Not available & $24(21)$ \\
\hline \multicolumn{2}{|l|}{ Hypertension } \\
\hline Yes & $96(85)$ \\
\hline No & $17(15)$ \\
\hline \multicolumn{2}{|l|}{ Hyperlipidemia } \\
\hline Yes & $77(68)$ \\
\hline No & $36(32)$ \\
\hline \multicolumn{2}{|l|}{ Coronary artery disease } \\
\hline Yes & $59(52)$ \\
\hline \multirow[t]{2}{*}{ No } & $54(54)$ \\
\hline & Continued \\
\hline
\end{tabular}




\begin{tabular}{lc} 
Table 1 Continued & \\
\hline & $\mathbf{n ~ ( \% )}$ \\
\hline $\begin{array}{l}\text { Renal disease } \\
\text { Yes }\end{array}$ & $28(25)$ \\
No & $85(75)$ \\
Peripheral vascular disease & \\
Yes & $62(55)$ \\
No & $51(45)$ \\
Reason for admission & $8(7)$ \\
Diabetes-related* & $22(19)$ \\
Cardiac & $11(10)$ \\
Stroke/TIA & $19(17)$ \\
Non-healing diabetic ulcer/osteomyelitis & $62(55)$ \\
Other &
\end{tabular}

*Excluding non-healing diabetic ulcers/osteomyelitis.

DR, diabetic retinopathy.

admitted with a non-healing diabetic ulcer/osteomyelitis were found to have diabetic retinopathy, indicating that diabetic ulcers are very strongly associated with presence of disease among our study population. The association was so strong that we excluded it from the multivariable logistic regression model due to the statistical concept of near-perfect separation.

Most patients $(96 \%)$ reported having a primary care physician; $64 \%$ reported having an ophthalmologist; $41 \%$ reported having a podiatrist; $37 \%$ reported having a cardiologist; 25\% reported having an endocrinologist; and $13 \%$ reported having a nephrologist.

\section{DISCUSSION}

The overall prevalence of diabetic retinopathy in this inpatient population was $44 \%$, which correlates with the $44 \%$ prevalence previously reported from an inpatient population studied in Tel-Aviv, Israel. ${ }^{13}$ The prevalence in our study is also in line with the $38 \%$ overall prevalence reported from an inpatient population in Bogenhausen Hospital, Munich, Germany. ${ }^{14}$ It is

\section{Table 2 Prevalence of diabetic retinopathy $(n=108)$}

\begin{tabular}{|c|c|c|c|}
\hline Stage & $\mathbf{n}$ & Prevalence (\%) & $95 \% \mathrm{Cl}$ \\
\hline $\begin{array}{l}\text { Diabetic retinopathy- } \\
\text { any severity }\end{array}$ & 47 & 44 & 34 to 53 \\
\hline $\begin{array}{l}\text { Previously } \\
\text { undiagnosed diabetic } \\
\text { retinopathy }\end{array}$ & 27 & 25 & 17 to 33 \\
\hline $\begin{array}{l}\text { Sight-threatening } \\
\text { diabetic retinopathy* }\end{array}$ & 20 & 19 & 11 to 26 \\
\hline $\begin{array}{l}\text { Previously } \\
\text { undiagnosed } \\
\text { sight-threatening } \\
\text { diabetic retinopathy }\end{array}$ & 4 & 3.7 & 0.1 to 7.3 \\
\hline \multicolumn{4}{|c|}{$\begin{array}{l}\text { *Severe NPDR, PDR, CSME. } \\
\text { CSME, clinically significant macular edema; NPDR, } \\
\text { non-proliferative diabetic retinopathy; PDR, proliferative diabetic } \\
\text { retinopathy. }\end{array}$} \\
\hline
\end{tabular}

Table 3 Classification of diabetic retinopathy $(n=108)$

\begin{tabular}{|c|c|c|}
\hline Stage & $\mathbf{n}$ & Prevalence (\%) \\
\hline No diabetic retinopathy & 61 & 56 \\
\hline $\begin{array}{l}\text { Mild non-proliferative diabetic } \\
\text { retinopathy }\end{array}$ & 16 & 15 \\
\hline $\begin{array}{l}\text { Moderate non-proliferative diabetic } \\
\text { retinopathy }\end{array}$ & 14 & 13 \\
\hline $\begin{array}{l}\text { Severe non-proliferative diabetic } \\
\text { retinopathy }\end{array}$ & 1 & 1 \\
\hline Proliferative diabetic retinopathy & 13 & 12 \\
\hline Clinically significant macular edema & 7 & 6 \\
\hline
\end{tabular}

significantly higher than the prevalence in the general US population (28.5\%). ${ }^{11}$ Reasons to explain the higher prevalence of diabetic retinopathy in the inpatient population include more comorbidities in a generally sicker population. The Tel-Aviv study reported that $22 \%$ of the inpatient population studied required laser treatment. ${ }^{13}$ This also correlates reasonably well with the $19 \%$ prevalence of sight-threatening retinopathy determined in our study. Perhaps most importantly, however, is that one in four patients in our study were found to have previously undiagnosed diabetic retinopathy ranging from mild non-proliferative disease to sight-threatening retinopathy.

The demographics for the population studied are likely to differ from those of the general outpatient diabetic population in several ways. It is likely to be an older population with a greater duration of diabetes, poor diabetic control, medical comorbidities and lower socioeconomic status. This was a major motivation for us to undertake this work. We believe that we have identified a high-risk population that can now be considered for targeted intervention. Furthermore, the prevalence of retinopathy may differ across different services within the same hospital. Further study may allow more precise identification of patients at higher risk.

Curiously, most inpatients in our population (91\%) are aware of the ocular complications of diabetes and many (64\%) do have ophthalmologists (more than any other subspecialty listed), yet only a minority (40\%) of patients are getting the recommended standard of care screening examinations. Barriers that are unique to this highrisk population may explain this disparity. As can be seen in figure 1, frequently reported barriers included transportation and physical disability, as well as being too sick or having too many other medical appointments. This is in contrast to the general diabetic population, for which previous studies have concluded that patients' lack of awareness due to lack of education or instruction is the primary barrier to patients receiving annual dilated eye examinations. ${ }^{10} 15{ }^{16}$ Also, while it is likely that any patient with diabetes would benefit from additional education and instruction, the inpatient population appears to have additional barriers related to its comorbidities that need to be addressed. Additionally, 
Figure 1 Barriers to diabetic retinopathy screening examinations as reported by those patients who did not have dilated fundus examinations in the previous year. DR, diabetic retinopathy.

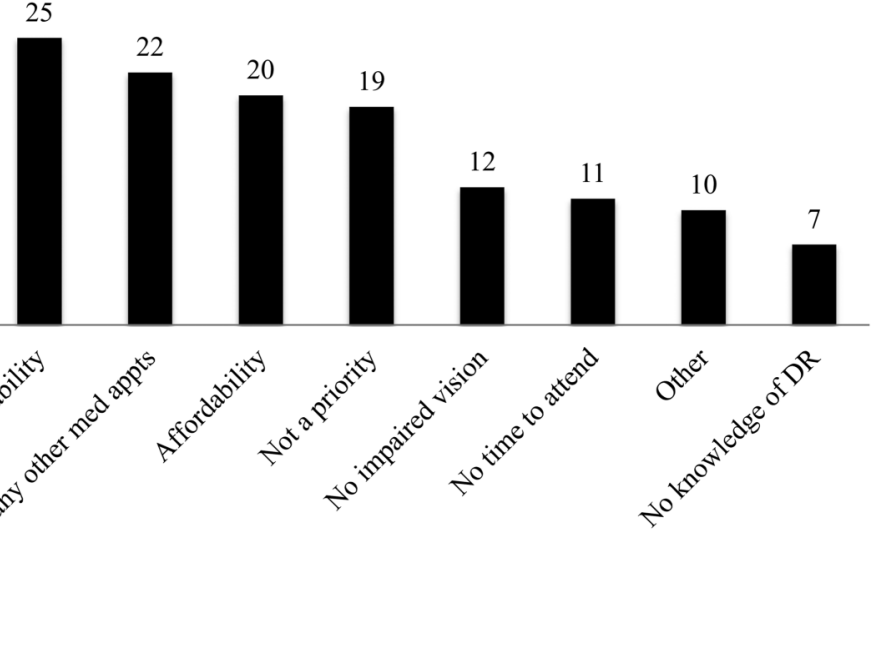

many study participants cited affordability and lack of time as barriers to care, which is consistent with previous studies. ${ }^{10}$

After examining factors associated with diabetic retinopathy, duration of diabetes and history of renal disease were each found to be independently predictive of diabetic retinopathy in the inpatient population, which is consistent with previous studies. ${ }^{17} 18$ Although microalbuminuria has been shown to be a risk factor for retinopathy in patients with type 1 diabetes but not type 2

Table 4 Univariate analysis

\begin{tabular}{|c|c|c|c|}
\hline \multirow[b]{2}{*}{ Variable } & \multicolumn{2}{|c|}{ Presence of diabetic retinopathy (DR) } & \multirow[b]{2}{*}{ p Value } \\
\hline & No & Yes & \\
\hline Hypertension & $52(85.2 \%)$ & $39(83.0 \%)$ & 0.748 \\
\hline Coronary artery disease & $29(47.5 \%)$ & $27(57.4 \%)$ & 0.307 \\
\hline Hyperlipidemia & $41(67.2 \%)$ & $33(70.2 \%)$ & 0.739 \\
\hline Renal disease & $8(13.1 \%)$ & $20(42.6 \%)$ & 0.001 \\
\hline Hemodialysis & $1(1.6 \%)$ & $8(17.0 \%)$ & 0.004 \\
\hline Peripheral neuropathy/peripheral vascular disease & $25(41.0 \%)$ & $35(74.5 \%)$ & 0.001 \\
\hline \multicolumn{4}{|l|}{ Admission diagnosis } \\
\hline $\begin{array}{l}\text { Diabetic (diabetic ketoacidosis, hyperosmolar } \\
\text { hyperglycemic non-ketotic syndrome) }\end{array}$ & $5(8.2 \%)$ & $3(6.4 \%)$ & 0.721 \\
\hline Cardiac (angina, myocardial infarction) & $11(18.0 \%)$ & $11(23.4 \%)$ & 0.492 \\
\hline Diabetic ulcer/osteomyelitis* & $2(3.3 \%)$ & $15(31.9 \%)$ & $<0.001$ \\
\hline Stroke/TIA & $4(6.6 \%)$ & $5(10.6 \%)$ & 0.447 \\
\hline Other & $43(70.5 \%)$ & $18(38.3 \%)$ & 0.001 \\
\hline Education & & & 0.896 \\
\hline Grade school & $2(3.3 \%)$ & $2(4.3 \%)$ & \\
\hline Some high school & $11(18.0 \%)$ & $7(14.9 \%)$ & \\
\hline High school & $20(32.8 \%)$ & $18(38.3 \%)$ & \\
\hline Some college & $16(26.2 \%)$ & $12(25.5 \%)$ & \\
\hline College & $8(13.1 \%)$ & $7(14.9 \%)$ & \\
\hline Masters & $4(6.6 \%)$ & $1(2.1 \%)$ & \\
\hline Family income & & & 0.303 \\
\hline$<25000$ & 35 (58.3\%) & 27 (57.4\%) & \\
\hline $25001-50000$ & $15(25.0 \%)$ & $17(36.2 \%)$ & \\
\hline $50001-75000$ & $3(5.0 \%)$ & $2(4.3 \%)$ & \\
\hline $75001-100000$ & $4(6.7 \%)$ & $0(0.0 \%)$ & \\
\hline \multirow[t]{2}{*}{$>100000$} & 3 (5.0\%) & $1(2.1 \%)$ & \\
\hline & Median (IQR) for DR & Median (IQR) for DR & \\
\hline Duration of diabetes & $6.0(2.5-10.0)$ & $15.0(10.0-20.0)$ & $<0.001$ \\
\hline Hemoglobin A1C (\%)† & $6.8(6.3-8.7)$ & $8.3(6.9-10.0)$ & 0.020 \\
\hline
\end{tabular}

${ }^{*}$ Not included in the multivariable logistic regression due to near-perfect separation. †Not included in the multivariable logistic regression due to high missing value count. 
diabetes, overt nephropathy has been well correlated with diabetic retinopathy. ${ }^{17}$ Our data also indicate that an admission diagnosis of non-healing diabetic ulcer is very strongly associated with the presence of diabetic retinopathy (15 of 17 patients) and is potentially a very important predictor of disease. This is consistent with a recent study among patients with hemodialysis that found a significant correlation between diabetic retinopathy and peripheral arterial disease. ${ }^{18}$

There are several limitations to this study. The study population was restricted to inpatients at UPMC Mercy Hospital in Pittsburgh, an inner city community teaching hospital. Care should be taken in the generalization of conclusions to other types of hospitals in other areas of the country. It could be argued that the prevalence values reported in this study may be higher due to the lower overall socioeconomic demographic of our study population. On the other hand, since some patients who were too ill to obtain fundus photos did not qualify for the study, the true prevalence of disease may actually have been underestimated.

There are limitations to posterior pole fundus photos for diabetic retinopathy screening, and some patients with mild peripheral disease may have been missed. This would have the effect of underestimating retinopathy. Several studies have shown that single-field fundus photography can serve as an effective screening tool to identify patients with diabetic retinopathy for referral for ophthalmic evaluation. ${ }^{19}$

The prevalence of undiagnosed disease was determined on the basis of a self-report of disease, and patient responses may not always be accurate. For example, there were two patients in the study with evidence of prior laser treatment who reported no history of diabetic retinopathy. For this study, these two cases were classified as having been previously diagnosed. Finally, with regard to the regression analysis, there are inherent limitations in differentiating cause and effect from simple association in a cross-sectional study.

The CI for the true prevalence of retinopathy in this population-34-53\%-is wide. A larger number of patients photographed would have resulted in a tighter estimate. The estimate is high enough, though, to allow us to conclude that the prevalence of retinopathy for this population is significantly higher than that for the general diabetic population.

On the basis of the results of this study, the prevalence of retinopathy among the population of inpatients with diabetes is likely significantly higher than among the general diabetic population in the USA and a significant percentage of these patients are likely to have undiagnosed or sight-threatening disease despite being under medical care. These patients have unique barriers that need to be addressed in order to make standard of care ophthalmic examination and treatment possible. Patients with renal disease and patients admitted for non-healing diabetic ulcers are at particularly high risk.

Hospitalization provides an opportunity to intervene. Possible interventions could include routine scheduling of an ophthalmological examination as part of discharge planning, photographic screening during the hospital stay or inpatient ophthalmological consultation for all or a subset of these patients. While inpatient consultation for every diabetic would be impractical, consultation or photographic screening for a select group has the potential to save sight.

Areas for future research include examination of prevalence of retinopathy over a larger variety of US hospitals to better determine the overall prevalence of diabetic retinopathy among the inpatient population in the USA. In addition, the outcomes and cost-effectiveness of routine inclusion of the scheduling of an eye examination as part of discharge planning and/or the routine use of retinal photographic screening during hospitalization should be examined.

\section{Author affiliations}

${ }^{1}$ Department of Ophthalmology, UPMC Eye Center, University of Pittsburgh School of Medicine, Pittsburgh, Pennsylvania, USA

${ }^{2}$ Department of Internal Medicine, UPMC Mercy Hospital, Pittsburgh,

Pennsylvania, USA

${ }^{3}$ Department of Endocrinology, UPMC Mercy Hospital, Pittsburgh, Pennsylvania, USA

Acknowledgements The authors thank Dan Winger, statistician at the Clinical and Translational Science Institute, University of Pittsburgh, for his help with statistical analysis. Jessica J Kovarik had full access to all of the data in the study and takes responsibility for the integrity of the data and the accuracy of the data analysis, as well as the decision to submit and publish the manuscript.

Contributors JJK performed data collection and analysis and wrote the manuscript. AWE performed data analysis, contributed to the discussion, and reviewed/edited the manuscript. LAW performed data collection and contributed to the discussion. JD performed data collection and analysis and contributed to the discussion. JMJ contributed to the discussion and reviewed/edited the manuscript. ELW thought of the idea to do this research, performed data analysis, contributed to the discussion, and reviewed/edited the manuscript.

Funding National Institutes of Health Grant Numbers P30 EY008098, UL1-RR-024153 and UL1-TR-000005; Eye and Ear Foundation of Pittsburgh; Clinical and Translational Science Institute, University of Pittsburgh; Unrestricted Grant from Research to Prevent Blindness, New York, New York, USA., analysis, and interpretation of the data; and no role in the preparation, review, or approval of the manuscript.

Competing interests JMJ is a speaker for Sanofi, Lilly, and Medtronic.

Ethics approval University of Pittsburgh School of Medicine.

Provenance and peer review Not commissioned; externally peer reviewed.

Data sharing statement No additional data are available.

Open Access This is an Open Access article distributed in accordance with the Creative Commons Attribution Non Commercial (CC BY-NC 4.0) license, which permits others to distribute, remix, adapt, build upon this work noncommercially, and license their derivative works on different terms, provided the original work is properly cited and the use is non-commercial. See: http:// creativecommons.org/licenses/by-nc/4.0/

\section{REFERENCES}

1. National diabetes fact sheet: general information and national estimates on diabetes in the United States. Cent Dis Control. 2005.

2. Klein R, Klein B. Vision disorders in diabetes. In: National Diabetes Data Group, ed. Diabetes in America. 2nd edn. Bethesda, MD: 
National Institutes of Health, National Institute of Diabetes and Digestive and Kidney Diseases, 1995:293-337.

3. Mohamed Q, Gillies MC, Wong TY. Management of diabetic retinopathy: a systemic review. JAMA 2007; 298:902-16.

4. The Diabetes Control and Complications Trial Research Group. The effect of intensive treatment of diabetes on the development and progression of long-term complications in insulin-dependent diabetes mellitus. N Engl J Med 1993;329:977-86.

5. UK Prospective Diabetes Study Group. Tight blood pressure control and risk of macrovascular and microvascular complications in type 2 diabetes: UKPDS 38. BMJ 1998;317:703-13.

6. Early Treatment Diabetic Retinopathy Study Research Group. Photocoagulation for diabetic macular edema: ETDRS report number 1: Early Treatment Diabetic Retinopathy Study Research Group. Arch Ophthalmol 1985;103:1796-806.

7. The Diabetic Retinopathy Study Research Group. Photocoagulation treatment of proliferative diabetic retinopathy: DRS report number 8 : The Diabetic Retinopathy Study Research Group. Ophthalmology 1981;88:583-600.

8. Javitt J. Cost savings associated with detection and treatment of diabetic eye disease. Pharmacoeconomics 1995;8(Suppl 1):33-9.

9. American Diabetes Association. Standards of medical care in diabetes-2011. Diabetes Care 2011;34:S35-6.

10. Moss SE, Klein R, Klein BE. Factors associated with having eye examinations in persons with diabetes. Arch Fam Med 1995;4:529-34.

11. Zhang $\mathrm{X}$, Saaddine JB, Chou CF, et al. Prevalence of diabetic retinopathy in the United States, 2005-2008. JAMA 2010;304:649-56.
12. Wilkinson CP, Ferris FL III, Klein RE, et al, Global Diabetic Retinopathy Project Group. Proposed international clinical diabetic retinopathy and diabetic macular edema disease severity scales. Ophthalmology 2003;110:1677-82.

13. Sadeh AD, Rosenblatt I, Rosenberger $Y$, et al. Frequency and patients' reported awareness of diabetic retinopathy among type 2 diabetic patients admitted to internal medicine wards. Diabetes Care 2000;23:1436-7.

14. Liesenfeld B, Kohner E, Piehlmeier, et al A telemedical approach to the screening of diabetic retinopathy: digital fundus photography. Diabetes Care 2000;23:345-8.

15. van Eijk KN, Blom JW, Gussekloo J, et al. Diabetic retinopathy screening in patients with diabetes mellitus in primary care: incentives and barriers to screening attendance. Diabetes Res Clin Pract 2012;96:10-16.

16. Lewis $\mathrm{K}$, Patel D, Yorston D, et al. A qualitative study in the United Kingdom of factors influencing attendance by patients with diabetes at ophthalmic outpatient clinics. Ophthalmic Epidemiol 2007;14:375-80.

17. Pedro RA, Ramon SA, Marc BB, et al. Prevalence and relationship between diabetic retinopathy and nephropathy, and its risk factors in the North-East of Spain, a population-based study. Ophthalmic Epidemiol 2010;17:251-65.

18. El-Menyar A, Al Thani H, Hussein A, et al. Diabetic retinopathy: a new predictor in patients on regular hemodialysis. Curr Med Res Opin 2012;28:999-1055.

19. Williams GA, Scott IU, Haller JA, et al. Single-Field Fundus Photography for Diabetic Retinopathy Screening: a report by the American Academy of Ophthalmology. Ophthalmology 2004;111:1055-62. 